ISSN: 0213-2079 - ISSN electrónico: 2386-3889

DOI: https://doi.org/10.14201/shhmo2019411728

\title{
PRESENTACIÓN. EUROPA Y LA MONARQUÍA HISPÁNICA ANTE EL CAMBIO DE HEGEMONÍA (1635-1659)
}

\section{Introduction. Europe and the Hispanic Monarchy faced with the change of hegemony (1635-1659)}

\author{
Alberto MARCOS MARTÍN \\ Universidad de Valladolid - Red Columnaria \\ Correo-e: marcos@fyl.uva.es
}

Lourdes AMIGO VÁZQUEZ

Universidad de Valladolid

Correo-e: lourdesamigo@gmail.com

RESUMEN: La constitución y mantenimiento de la Monarquía Hispánica como un poder hegemónico global dependieron de su capacidad para movilizar recursos fiscales crecientes, así como para pedir dinero prestado y expandir su crédito. Empero, cuando esa capacidad disminuyó, también lo hicieron sus posibilidades de seguir imponiendo su voluntad en el escenario internacional. Esta clave explicativa del cambio de hegemonía en Europa está presente, junto a otros argumentos igualmente esclarecedores, en los trabajos que componen el presente informe. Sus autores hacen gala de un conocimiento exhaustivo de la bibliografía existente, aportan información documental nueva y reflexionan sobre los hechos que estudian para trazar

1. Esta presentación se ha realizado en el marco de los Proyectos de Investigación HAR2014-52414-C2-1-P, Hispanofilia III: la influencia ibérica en su contexto político, siglos XVI-XX y HAR2017-82791-C2-1-P, Hispanofilia IV: los mundos ibéricos frente a las oportunidades de proyección exterior y a sus dinámicas interiores, y en el seno del Grupo de Investigación Reconocido (GIR) de la Universidad de Valladolid «Grupo de estudios sobre la familia, cultura material y formas de poder en la España Moderna». 
un cuadro bien aquilatado de un periodo histórico decisivo en el devenir del Viejo Continente.

Palabras clave: Monarquía Hispánica; Europa; hegemonía; guerra; fiscalidad; deuda pública; siglo XVII.

ABSTRACT: The organisation and preservation of the Spanish Monarchy as a global hegemonic power depended upon its capacity to mobilise ever-greater fiscal resources, as well as its ability to arrange loans and to expand its credit bases. However, when its incomes and revenues diminished its scope to continue imposing its will upon the international theatre of arms was also greatly reduced. The studies in this collection set out this key interpretation of the reasons for the change in European hegemony together with other illuminating and innovative insights and arguments. The authors display an exhaustive knowledge of the current bibliography, bring new documentary findings to bear and draw upon their own research interests to present a balanced assessment of this decisive period in the development of the Old Continent.

Keywords: Spanish Monarchy; Europe; Hegemony; War; Fiscalism; Public debt; seventeenth-century.

En la sesión del Consejo de Estado celebrada el 13 de junio de 1578, a la que asistieron el arzobispo de Toledo, cardenal Quiroga, y los marqueses de Aguilar, Los Vélez y Almazán, se trató de forma monográfica, como había ocurrido otras veces en los últimos diez o doce años, de las cosas de Flandes. Concretamente, el punto que en esta ocasión reclamó la atención de los consejeros citados, si bien solo a manera y modo de conferencia (o sea, sin que pudieran llegar a tomar resolución sobre él), fue el de si Su Majestad católica debía proseguir la guerra en aquel territorio o si, por el contrario, convenía componer lo de allí por vía de concierto, asunto este que venía siendo no menos recurrente en las conversaciones del Consejo, sobre todo a raíz de los acontecimientos ocurridos en 1576-1577»².

Tomó la palabra en primer lugar el primado de la mitra toledana quien, luego de encarecer la importancia del negocio, hizo notar el dilema («perplejidad») al que se exponía todo aquel que intentaba encontrar una solución a dicho conflicto, empezando por él mismo. Para el cardenal Quiroga, en efecto, lo que los Estados

2. AGS (Archivo General de Simancas), Estado, leg. 578. 
Generales de los Países Bajos decían y ofrecían respecto al concierto del que se venía hablando desde hacía algunos meses eran solo palabras; es más, estaba convencido de que los Estados no tenían intención de cumplir ninguna de las cosas que prometieran con este motivo, máxime cuando daban por hecho que el susodicho concierto había de fundarse en la observancia de la Capitulación (sic) de Gante, firmada y publicada el 8 de noviembre de 1576, «que contiene - proclamaba sin ambages - las indignidades que se sabe, pues en virtud de ella [...] vendrían a tener libertad de conciencia [...] y han de salir los españoles [de Flandes], y el de Orange quedaría señor de la mar, y de Holanda y Zelanda». A pesar de la firmeza con la que aparentemente se expresaba, el arzobispo, conocedor de la crítica situación por la que atravesaban las finanzas regias (se había decretado, en septiembre de 1575, la segunda - o la tercera, según se mire - suspensión de consignaciones del reinado), no dejaba de declarar al mismo tiempo que "es fuerza (o sea, resultaba obligado) dar oídos al concierto", precisamente por estar lo de la Hacienda «tan acabado». Recordaba Quiroga al respecto que Felipe II se había visto obligado a «apretar lo de las alcabalas» (es decir, solicitar-exigir del reino, en 1575-1577, el crecimiento del encabezamiento de este impuesto) y a poner en marcha «otros expedientes» (enajenaciones del patrimonio real fundamentalmente), «que tienen a los vasallos de estos reinos [de Castilla] en mucha necesidad y mala satisfacción», frase que contenía una clara y elocuente alusión al notable incremento de la carga fiscal que se había producido en los años inmediatamente anteriores, pero también al creciente malestar que por esta razón había comenzado a extenderse entre los súbditos castellanos. Eso sí, concluía el arzobispo, en el caso de que por necesidad se tuviese que llegar al mentado concierto, sería mejor ejecutarlo ahora que cuando hubiese menos fuerzas, «pues con las que V. Md. tiene al presente en Flandes se haría con autoridad» ${ }^{3}$.

El marqués de Aguilar se mostró del todo concordante con lo referido por el arzobispo (por ser, dijo, «la pura verdad»). Él también era de la opinión de que, «no se pudiendo más», se hiciese el concierto, pero siempre bajo la sobredicha circunstancia y con la condición de que se quedasen allí las tropas españolas, pues sin ellas «no habrá obediencia, y no habiendo obediencia no habrá religión», siendo preferible ejecutarlo ahora «que V. Md. está armado», una ventaja que, insistía, no había que desaprovechar.

3. Se refería Quiroga al regreso a los Países Bajos de las tropas que habían tenido que salir de allí en abril de 1577 a raíz de la aceptación, por don Juan de Austria, de los términos de la Pacificación de Gante, y a la aplastante victoria sobre el ejército de los Estados Generales conseguida en Gembloux el 31 de enero de 1578, que había revertido un tanto la situación. Para la evolución del conflicto y el detalle de los acontecimientos, véase PARKER, G.: España y la rebelión de Flandes. Madrid, 1989, en particular pp. 167-194. 
Más convencido aún de la necesidad de tratar del concierto manifestó encontrarse el de Los Vélez. Bien que en su opinión no era posible que de parte de los que no querían ser católicos de corazón pudiese haber seguridad, lo cierto es que tampoco el rey Católico tenía las fuerzas necesarias para hacerles guardar la religión, aparte de que con destruir Flandes no se conseguiría nada ni se acabaría con los herejes rebeldes, por mucho que permaneciesen allí los soldados españoles. Por consiguiente, el concierto, en la manera que mejor se pudiera tomar, se le antojaba necesario para no perderlo todo, «pues no ay dineros en el mundo que basten - añadía como último y poderoso argumento- para acabarlo por vía de la fuerza».

En fin, el marqués de Almazán convino con sus compañeros en la mayoría de las consideraciones realizadas, añadiendo una que, por juzgarla importante, pedía que se tuviera igualmente en cuenta a la hora acordar una decisión sobre este negocio: que aun cuando Su Majestad dispusiera del poder que era menester para pacificar aquellos estados por la fuerza, «habrá tanto que hacer en conservarlos por ella como en conquistarlos [...] que es muy verosímil que nunca sufrirán que los españoles queden como estaban», frases indicativas sin duda de cuál era realmente su posición al respecto, no muy distante de la manifestada anteriormente por el marqués de Los Vélez. Dos consideraciones al cabo prudentes y realistas, que de haberse atendido debidamente quizá hubiesen evitado no pocos de los sufrimientos y menoscabos que, por mor de la prosecución de la guerra, se seguirán produciendo en el porvenir.

Nada se determinó en esta sesión del Consejo de Estado sobre la materia dicha al haberse tratado solo por vía de conferencia. Se volvió, no obstante, a hablar de ella en la siguiente reunión, en la que los consejeros tuvieron a la vista un ejemplar de la Capitulación de Gante (así seguían llamándola) y otros documentos que habían solicitado previamente ${ }^{4}$. El primero en intervenir ahora fue el marqués de Aguilar, quien persistió en su opinión de que se debía dar pie a la plática del concierto, atenta la «estrecheza de la Hacienda» y la falta de la artillería y otras cosas necesarias a la continuación de la guerra, «y que no tenemos la mar que es el todo». En la misma dirección apuntó el marqués de Almazán para quien el tratar del concierto venía a ser negocio forzoso, «pues nos consumimos a más andar». Los matices a semejantes pronunciamientos los puso el cardenal Quiroga (no estuvo presente en esta sesión el marqués de Los Vélez), para quien decidir sobre si convenía o no tratar del concierto con los rebeldes flamencos no era en realidad asunto que pudiese someterse a juicio sino que dependía del estado en que se hallase la Real Hacienda. «Porque si no ay la que es menester para lleuar la guerra adelante», decía, necesariamente se tendría que hablar de concierto, una decisión a la que abocaba la carencia de dineros

4. AGS, Estado, leg. 578. 
ciertamente pero de la que se derivarían (se trataba de presentarla de forma atractiva para, en el caso de que finalmente hubiera de adoptarse, hacerla más asumible) los «infinitos bienes» de la paz: esta, en efecto, aparte de «haberla encomendado tanto Cristo Nuestro Señor», permitiría a Su Majestad fortificar sus estados, aliviar a sus súbditos y, con lo que se ahorrase, disponer de los medios oportunos para conquistar infieles. Sin embargo, el arzobispo no veía inconveniente ni contradicción alguna en renunciar a alcanzar tan virtuosos designios (y a cumplir, por tanto, con la referida encomienda divinal) si el monarca disponía de dineros con que continuar la guerra de Flandes: en tales circunstancias, en efecto, le parecía que no se debía dejar aquella guerra, ya que con ella «castigará V. Md. sus rebeldes, dará leyes a sus vasallos y ellos cumplirán lo que se les mandare», lo que serviría a su vez de ejemplo para que otros no se atreviesen a incurrir en semejantes desacatos. La ocasión, por lo demás, era «de gran momento», y si se aprovechaba debidamente «se pondría aquella república en el concierto y obediencia que deue tener a V. Md.».

A estos juicios emitidos presencialmente se uniría el parecer que por escrito dio Gonzalo Fernández de Córdoba, III duque de Sessa, el 22 de junio de 1578, o sea, apenas unos meses antes de su muerte ocurrida a finales de este mismo año ${ }^{5}$. Decía el experimentado político y militar que sería muy conveniente al servicio real componer «lo de allí» por medios pacíficos pues tenía por muy dudoso y lleno de dificultades el camino de la guerra, «attento lo mucho que ha gastado y hauría de gastar V. Md.», y estando lo de la Hacienda, según la información que había recabado, en términos que no se podría hacer la correspondiente provisión de dinero tan cumplidamente como se precisaba. Pero aun suponiendo que hubiese sobrantes de tesorería, era plenamente consciente, distanciándose así de la posición ambigua o posibilista mantenida por Quiroga, de las enormes dificultades de ganar aquella guerra, máxime si el monarca no se hacía señor de la mar y se persistía en la estrategia de (re)conquistar el país palmo a palmo, como en efecto se estaba haciendo (o intentaba hacer). Además, en el ánimo de don Gonzalo pesaba también, y mucho, el argumento de la reputación, pues opinaba que si el resultado de la guerra no era el esperado, la pérdida sería vergonzosa, «por ser de V. Md. con sus vasallos»; vergonzosa... y a la vez peligrosa, «en respecto de los otros [vasallos] que están a la mira y no nada descuidados en tomarlo por ejemplo para echar de sí el yugo de los españoles», cosa que él mismo había tenido ocasión de constatar en Italia, donde circulaban, aseguraba, «hartas hablillas» sobre ello. En consecuencia, el de Sessa se decantaba abiertamente por la vía del concierto, considerando además que el momento (es decir, después de la vuelta de los veteranos de Flandes y la

5. AGS, Estado, leg. 578. 
victoria en la batalla de Gembloux) era bueno para hacerlo, antes en todo caso de que disminuyesen las fuerzas del rey católico, «pues de otra manera se atribuiría a imposibilidad».

Pero si finalmente se tomaba la decisión de transitar por el camino de la negociación, había que pensar en la persona que más acertadamente pudiese actuar de árbitro o intermediario entre el monarca y los rebeldes. De ello hablaron también los consejeros susodichos y después de descartar otras opciones - «el medio del Papa, que fuera el propio, está remoto; el de Francia ni Inglaterra no conviene» - coincidieron finalmente en que la persona más idónea para cumplir con semejante cometido era el emperador Rodolfo II, no obstante las sospechas y recelos que despertaba, a causa sobre todo de la intolerable intromisión en el conflicto de su hermano Matías ${ }^{6}$. Este se había ofrecido a los Estados Generales como gobernador, y tras llegar a territorio holandés en octubre de 1577, prestó juramento el 20 de enero de 1578, comprometiéndose a gobernar los Países Bajos en nombre del rey, pero teniendo nada menos que al príncipe de Orange como suplente y principal consejero ${ }^{7}$.

No era la primera vez, desde que en 1566-1568 estallara la rebelión, que se hablaba de la posibilidad de llegar a un concierto con los rebeldes de los Países Bajos; y, desde luego, tampoco sería la última antes de que la guerra en aquellas tierras se diese definitivamente por concluida a principios de 1648 (Paz de Münster). Siempre hubo, además, a lo largo de esos ochenta años, contactos, vías de comunicación abiertas, propuestas de paz e, incluso, negociaciones en regla entre las dos partes aunque a la postre tales tentativas no dieran resultados positivos y duraderos, con la excepción, si cabe, de los acuerdos que condujeron al alto el fuego de 1607 y a la subsiguiente tregua de 1609-1621 (la llamada Tregua de los Doce Años). Si hemos traído a colación las deliberaciones del Consejo de Estado de junio de 1578 sobre esta cuestión, tan alejadas cronológicamente de los límites temporales a los que se atienen las distintas colaboraciones del presente informe, ha sido porque en ellas se encuentran ya expresados muchos de los elementos que estarán presentes en (y determinarán) los posteriores procesos de toma de decisiones respecto de la guerra de Flandes, cuyos derroteros y desenlace final, unidos a los de la guerra de los Treinta Años y a los de la posterior guerra contra Francia, hasta llegar a la Paz de los Pirineos de 1659, impulsarán la evolución histórica que finalmente sancionará el cambio de hegemonía en Europa.

6. Como decía el duque de Sessa en el parecer por escrito dado el 22 de junio de 1578, del que procede asimismo el entrecomillado anterior, «vale más dejarse engañar del amigo y pariente tan propincuo [el emperador] que perder vergonzosamente el estado y autoridad con los vasallos. Y que así es menester hacer demostración de confianza con el emperador...». AGS, Estado, leg. 578, fol. 121.

7. PARKER, G.: España y la rebelión..., op. cit., p. 183. 
Y no nos referimos solo al recurrente dilema (la «perplejidad» a la que aludía Quiroga) entre aplicar a los rebeldes mano dura, no usando de más argumentos que los de las armas y la fuerza, o llegar a un acuerdo negociado con ellos que fuera verdadero anticipo de la paz. El componente confesional del conflicto, la causa de la religión católica y la defensa de la verdadera fe, el rechazo en fin a cualquier atisbo de concesión de libertad de conciencia que pudiera derivarse de una efectiva y sincera aceptación por parte del rey de los términos de la Pacificación de Gante, asoman, como no podía ser de otra manera, en los pareceres de los consejeros. Esto no significa (ya entonces) que contemplaran dicha guerra como un conflicto exclusivamente religioso sino más bien como la consecuencia inevitable y desgraciada de la rebelión protagonizada por unos vasallos contra su señor natural, a la que este tenía que dar obligada y pronta respuesta.

Ciertamente, en aquella guerra entraron en juego $-\mathrm{y}$ se aventuraron - otros elementos además de los religiosos. La reputación del monarca sin ir más lejos, la obligación que este tenía de conservar la Monarquía en toda su integridad, tal como la había recibido, y, por ende, el temor a que la pérdida de cualquiera de sus partes pudiera traer consigo la de las demás según la teoría, tan arraigada, del efecto dominó, se cuentan también entre ellos. De ahí el alto grado de enconamiento que alcanzó esta guerra de Flandes, su larguísima duración, el desgaste y los innumerables daños que provocó, aunque lo mismo - o algo parecido - cabría decir de las otras guerras que se sucedieron paralelamente en su transcurso o de las que estallaron después, y en las que estuvo comprometida igualmente la Monarquía de España. Y de ahí también que cada vez que en el Consejo de Estado (o en otros ámbitos) se planteaba la eventualidad de llegar a un acuerdo negociado (como en la concreta coyuntura de junio de 1578 a la que nos estamos refiriendo) fuese casi siempre para sostener que ese posible acuerdo había de hacerse con autoridad, es decir, en posición de fuerza y en el momento más conveniente para ello, dos presupuestos que, dado que la otra parte pensaba de manera semejante, no eran precisamente los mejores para iniciar de consuno un verdadero proceso de paz.

En resumidas cuentas, si la voluntad de ganar a toda costa se imponía sobre cualquier otro objetivo o consideración, si semejante designio conducía a la prosecución de una guerra como la de Flandes no obstante sus altísimos costes y las graves consecuencias que acarreaba. Está claro, por ejemplo, que su finalización solo podía sobrevenir una vez que se produjera el agotamiento de los recursos (hombres y dineros) disponibles. Precisamente la marcha de los acontecimientos en Flandes durante este concreto año de 1578 proporciona abundantes y anticipadores testimonios a contrario de que las cosas sucedían del modo que dicha afirmación indica. Es evidente que la vuelta de los veteranos desde Italia, en septiembre del año anterior, permitió que el ejército comandado por Juan de Austria venciera a las tropas de los Estados Generales en la ya citada batalla de Gembloux (31 de enero). No es menos 
cierto, sin embargo, que tal suceso no habría ocurrido sin el previo restablecimiento, tras la publicación del medio general de 5 de diciembre de 1577 y la formalización de un nuevo asiento de cinco millones de ducados con los hombres de negocios, de los servicios financieros que garantizaban, para el futuro inmediato, el flujo de dinero hacia Flandes ${ }^{8}$; e, igualmente, sin el correlativo e imprescindible aumento de las disponibilidades regias en Castilla (crecimiento de las alcabalas en 1575-1577 que permitió elevar considerablemente el techo de endeudamiento, perpetuación de facto de las «tres gracias» pontificias, llegada de plata de las Indias para el tesoro en cantidades mayores que nunca a partir de 1577, rendimiento espectacular por las mismas fechas de algunos arbitrios relacionados con la enajenación del patrimonio regio: ventas de baldíos, de jurisdicciones y vasallos de iglesias y monasterios, de rentas reales, de oficios, etc.), circunstancias que impulsaron a la Corona a practicar una política agresiva en aquellas tierras ${ }^{9}$. De hecho, en junio de 1578, mientras los hombres del Consejo de Estado se hallaban conferenciando, como se ha visto, sobre la posibilidad de llegar a un acuerdo con los rebeldes, tal opción ya había sido descartada o, mejor dicho, superada por el devenir de los acontecimientos... Y sustituida por el empleo de la fuerza y la apelación a la intransigencia. Es más, hechos como la toma de Maastrich por el príncipe de Parma (junio de 1579) o la conclusión sin resultados de la conferencia entre España y los Estados Generales organizada por el emperador Rodolfo II en Colonia (mayo de 1579) serían interpretados por muchos como la confirmación de que ese era precisamente el camino que había que seguir.

La capacidad de la Corona para movilizar recursos fiscales cada vez más cuantiosos pero también para pedir dinero prestado, es decir, para expandir su crédito con ese respaldo (y con el que deparaba la plata americana), hicieron de Felipe II en los años ochenta «el monarca más poderoso de la Cristiandad» ${ }^{10}$. La conquista

8. RUIZ MARTÍN, F.: «Las finanzas españolas durante el reinado de Felipe II», Cuadernos de Historia. Anexos de la Revista Hispania, 2, 1968, pp. 181-203; LOVETT, A. W.: «The General Settlement of 1577: An Aspect of Spanish Finance in the Early Modern Period», Historical Journal, 25 (1), 1982, pp. 1-22; y últimamente CARLOS MORALES, C. J. de: Felipe II: El Imperio en bancarrota. La Hacienda Real de Castilla y los negocios financieros del Rey Prudente. Madrid, 2008, pp. 171-184.

9. Influyeron asimismo en este nuevo cambio de rumbo hacia la guerra, que cerró el paréntesis abierto con el alto el fuego de 20 de octubre de 1576 y convirtió en papel mojado lo pactado en el Edicto Perpetuo de 12 de febrero de 1577, las crecientes divisiones surgidas entre católicos y calvinistas en el seno de los Estados Generales que terminaron dando lugar a la constitución, por un lado, de la Unión de Utrecht (23 de enero de 1579) y a la firma, por otro, del Tratado de Arrás (15 de mayo de 1579). Como sin duda influyó también la firma de la paz con los turcos (marzo de 1577), que sería prorrogada en los años siguientes, una circunstancia geoestratégica que hizo posible concentrar esfuerzos en esta otra parte de Europa.

10. Sobre el empleo de esta expresión, paralela o complementaria a la del imperio en que no se ponía el sol, véase PARKER, G.: Felipe II. Madrid, 2003, p. 191. 
e incorporación de Portugal y de todo su imperio colonial, la recuperación del sur de los Países Bajos, la intervención en los asuntos franceses y la ayuda prestada a los dirigentes católicos de la Liga, amén de la ofensiva contra Inglaterra, pondrían de patente, en efecto, que ese título en manera alguna era exagerado. Sin embargo, el extraordinario esfuerzo financiero realizado por la Corona en cada una de estas ocasiones no pudo sostenerse hasta el final del reinado. La guerra abierta contra la Francia de Enrique IV, el recrudecimiento de las hostilidades en los Países Bajos donde los rebeldes holandeses reconquistaron algunas provincias del sur, el aumento del corsarismo inglés en el Atlántico tras el desastre de la armada (incluidos los ataques a La Coruña en 1589 y Cádiz en 1596) e, incluso, las guerras en las zonas fronterizas de América que obligaron a paralizar la expansión al norte de la Nueva España y al sur del río Bio-Bio (Chile), demandaron, en la década de los noventa, un volumen de recursos cada vez más difícil de reunir por la Real Hacienda no obstante la prosecución, durante estos últimos años del siglo XVI, de las llegadas masivas de plata americana y la aprobación, en 1589, por las Cortes de Castilla de un nuevo servicio, el de los millones, por valor de ocho millones de ducados a cobrar inicialmente en seis años. Tantos compromisos en tantos frentes forzarían a la Corona a incrementar las cantidades de dinero tomadas en asiento (deuda flotante) y a realizar, para respaldar tales operaciones y cubrir el déficit que aún resultaba, nuevas emisiones de juros (títulos de la deuda consolidada), cuyo volumen, por estas y otras razones, siguió aumentando sin cesar, y siempre de manera más intensa y rápida de lo que lo hacían los ingresos sobre los que se situaba. Además, para hacer frente a las consecuencias derivadas de semejante desfase la Corona empezó a actuar sobre la misma deuda adoptando una serie de medidas (crecimientos de juros, reducciones del tipo de interés que los retribuía, impago de los réditos que no cabían en sus situaciones, etc.) que no eran precisamente las más adecuadas para mantener su credibilidad y, por ende, la fortaleza del sistema de crédito público fundado en torno a ella.

Falta de hacienda, pues, pero también descaecimiento y pérdida de sustancia, tanto económica como demográfica. No en balde, en la mayoría de las regiones de Castilla se estaba asistiendo ya, por estos años postreros del mil quinientos, al final de la etapa expansiva de la población y la economía y al comienzo de la recesiva, cambio de signo de la coyuntura motivado en gran parte por la persistente absorción de renta de los particulares a resultas no solo del despliegue de la fiscalidad (en sus diferentes formas, incluidos arbitrios y expedientes diversos) sino también de la venta de títulos de la deuda pública (juros), y su subsiguiente desvío de la inversión productiva y de las actividades creadoras de riqueza. Un panorama muy poco halagüeño, en definitiva, que hacía de la búsqueda de la paz una tarea inexcusable. La apertura de negociaciones formales con Francia a finales de 1597 que desembocaron en la paz de Vervins (2 de mayo de 1575), el tratado de Londres de 1604 con Inglaterra luego de diversas tentativas y contactos previos, incluidos los efectuados en 
vida de la reina Isabel, y la Tregua de los Doce Años (1609) con los estados rebeldes de los Países Bajos, que estuvo precedida a su vez por la cesión de la soberanía de dicho territorio hecha por Felipe II en favor de su hija Isabel Clara Eugenia en 1598, respondieron en buena medida a este escenario, en el que los problemas financieros de los contendientes (y no solo de la Monarquía Hispánica) tuvieron un especial protagonismo. Pero lo mismo cabría decir del resto del período conocido como de Pax Hispánica, que tradicionalmente ha sido considerado bien como una pausa impuesta por la precariedad de las Haciendas de los países contendientes, empezando por la de Castilla, bien como una estrategia para recuperar las fuerzas y ganar las guerras heredadas del reinado anterior ${ }^{11}$. Fuera lo que fuese, lo cierto es que ni la pax en el concierto internacional fue total ni los gastos de la Hacienda castellana disminuyeron en la proporción que esas interpretaciones invitan a suponer, antes bien aumentaron de forma considerable en algunas partidas ${ }^{12}$. Se perdió de esta manera una magnífica oportunidad no ya para hacer ahorros pensando en el inmediato porvenir (ese que se abrió con los acontecimientos de Bohemia de 1618 y el fin de la Tregua de los Doce Años y que disparó de nuevo el gasto de la Monarquía) sino para llevar a cabo la tan cacareada reforma de la Hacienda como exponente y parte de la anhelada «reformación general» ${ }^{13}$. El mismo proyecto de «desempeño» del que tanto se había hablado pasó a mejor vida ${ }^{14}$, por lo que el volumen de deuda, lejos de reducirse, no hizo otra cosa que aumentar. Entre 1598 y 1623, por ejemplo, el situado de los juros en circulación, es decir, la suma de los intereses devengados por tales títulos, pasó, no obstante la paralela reducción de la tasa de interés, de 1.738 millones de maravedíes a 2.110 millones $^{15}$, siendo cada vez mayor por tanto la parte de los ingresos ordinarios (y enseguida de algunos extraordinarios como los millones) afectada al pago de esta clase de deuda.

11. GARCÍA GARCÍA, B. J.: La Pax Hispanica: politica exterior del duque de Lerma. Leuven, 1996; y ALLEN, P. C., Felipe III y la pax hispánica, 1598-1621. Madrid, [2001].

12. GELABERT, J. E.: La bolsa del rey. Rey, reino, fisco en Castilla (1598-1548). Barcelona, 1997, pp. 29-60.

13. MARCOS MARTÍN, A.: «Restaurar la Hacienda para conservar la Monarquía. El intento de creación (1616) de una Junta de Provisiones», en GARCÍA GUERRA, E. Ma . y DE LUCA, G. (a cura di): Il mercato del crédito in Età Moderna. Reti e operatori finanziari nello spazio europeo. Milano, 2009, pp. 207-235.

14. No puede considerarse como tal el arbitrio concedido y puesto en ejecución por los diputados del medio general de 14 de mayo de 1608 para reembolsarse de lo que el monarca les debía consistente en comprar juros redimibles que corrían a bajos precios (a 14.000 el millar, por ejemplo) para volverlos a vender a mayores precios (a 20.000 el millar).

15. Según datos ofrecidos por diversos autores (F. Ruiz Martín, M. Ulloa, Domínguez Ortiz) que se recopilan en MARCOS MARTÍN, A.: «¿Fue la fiscalidad regia un factor de crisis en la Castilla del siglo XVII?», en PARKER, G. (coord.): La crisis de la Monarquía de Felipe $I V$. Barcelona, 2006, p. 232. 
Según la reciente reconstrucción realizada por Andrés Ucendo, los ingresos ordinarios de la Real Hacienda de Castilla se mantuvieron estables en términos nominales durante el primer tercio del siglo XVII, aunque si se les deflacta, para descontar el efecto de la inflación del vellón sobre ellos, se comprueba que, en términos reales, siguieron una tendencia descendente ${ }^{16}$. Ya en la década de los treinta el valor de dichos ingresos volvió a crecer, y lo hizo además de manera notable al pasar de 3.300 millones de maravedíes en 1630 a casi 6.155 en $1640^{17}$. Ello fue posible merced a la nueva vuelta de tuerca en la imposición fiscal impulsada por la Corona inmediatamente antes e inmediatamente después de $1635^{18}$, el año de la entrada de Francia en la guerra de los Treinta Años apoyando a los príncipes protestantes alemanes y a los rebeldes holandeses, que fue lógicamente un periodo caracterizado por el recrudecimiento de las hostilidades en todos los frentes y que coincidió, por si fuera poco, con los momentos de mayor postración económica y demográfica de Castilla. Tan importante subida de los ingresos ordinarios de la Corona en términos nominales dio lugar a que los ingresos reales, a precios constantes o medidos en términos de plata, subieran también, aunque lógicamente no en la misma proporción, lo que se tradujo en un considerable aumento de la carga fiscal tanto per capita como con relación a la riqueza del país (lo que hoy llamaríamos el Producto Interior Bruto) ${ }^{19}$ : era en definitiva la otra cara de la política de reputación practicada por Felipe IV y su valido Olivares durante la primera parte del reinado. A partir de 1643 o 1644, sin embargo, justo en el momento en que comenzaba a dirimirse la hegemonía en Europa, ya no le sería posible a la Real Hacienda continuar incrementando los

16. ANDRÉS UCENDO, J. I.: «Una hacienda permanentemente endeudada: impuestos y deuda pública en la Castilla del siglo XVII», en ÁLVAREZ NOGAL, C. y COMÍN COMÍN, F. (eds.): Historia de la deuda pública en España (siglos XVI-XXI). Madrid, 2015, pp. 67-83. Este autor considera como ingresos ordinarios los impuestos que recaudaba la Real Hacienda, las rentas patrimoniales, las estancadas, los ingresos aduaneros y los servicios, junto con la media anata de juros y las rentas de origen religioso (cruzada, subsidio y excusado). No incluye en esa cuenta el producto de la venta de rentas reales (ni el de otros bienes y efectos del patrimonio regio enajenados), los metales preciosos americanos, lo obtenido de las manipulaciones de la moneda de vellón y lo procedido de los donativos, considerados por él como ingresos extraordinarios.

17. ANDRÉS UCENDO, J. I.: «Una hacienda permanentemente endeudada...», op. cit., p. 70. También ANDRÉS UCENDO, J. I. y LANZA GARCÍA, R.: «Estructura y evolución de los ingresos de la Real Hacienda de Castilla en el siglo XVII», Studia Historica. Historia Moderna, 30, 2008, pp. 147-190.

18. DOMÍNGUEZ ORTIZ, A.: Política y Hacienda de Felipe IV. Madrid, 1960, pp. 37-62; GELABERT, J. E.: La bolsa del rey..., op. cit., pp. 81-126; MARCOS MARTÍN, A.: «Deuda pública, fiscalidad y arbitrios en la Corona de Castilla durante los siglos XVI y XVII», en SANZ AYÁN, C. y GARCÍA GARCÍA, B. J. (eds.): Banca, Crédito y Capital. La Monarquía Hispánica y los antiguos Países Bajos (1505-1700). Madrid, 2006, pp. 360-361.

19. ANDRÉS UCENDO, J. I.: «Una hacienda permanentemente endeudada...», op. cit., p. 71. 
ingresos. Si bien su valor en términos nominales se estabilizó alrededor de los altos niveles de finales de los años treinta y de inicios de los cuarenta, manteniéndose en consecuencia por encima de los valores del primer cuarto de siglo para comenzar a descender solo después de la deflación de 1680, en términos reales, que son al cabo los que miden las posibilidades que tenía la Monarquía de jugar sus bazas en el escenario internacional, experimentaron un progresivo descenso desde la cima que habían alcanzado en los primeros años de la década de los cuarenta, cima que por dicha razón puede decirse que constituye una especie de techo fiscal que ya no se sobrepasaría ${ }^{20}$.

El estudio aislado del sistema fiscal, de los impuestos y su cuantía, con ser importante y necesario, no lo dice todo. Antes bien, es indispensable integrarlo con el del crédito y la deuda. A fin de cuentas, la incapacidad de la Real Hacienda para aumentar sus ingresos a la que acabamos de referirnos, consecuencia a su vez del profundo deterioro de la situación económica de Castilla (y del que era responsable en no poca medida el propio e incesante despliegue de la fiscalidad regia) ${ }^{21}$, afectó de modo muy negativo al funcionamiento de su sistema de deuda. Ello es claro en cuanto a la deuda flotante, la contraída por la Corona a corto plazo con sus banqueros. Así, hasta 1642 el volumen de contratación de asientos, más allá de las lógicas variaciones de unos años a otros, no cesó prácticamente de aumentar. Empero, después de esa fecha las cantidades de dinero asentadas anualmente (que eran las que de forma inmediata permitían financiar el esfuerzo bélico) fueron cada vez menores debido a la falta de consignaciones seguras que ofrecer a los hombres de negocios, si bien durante algunos años dichas cantidades se mantuvieron todavía en niveles relativamente altos ${ }^{22}$.

La imposibilidad de seguir aumentando los ingresos fiscales a partir de las fechas señaladas comprometió igualmente la sostenibilidad de la otra clase de deuda, la de los juros - deuda a largo plazo o deuda consolidada -, cuyo principal no había

20. ANDRÉS UCENDO, J. I.: «Una hacienda permanentemente endeudada...», op. cit., p. 71.

21. MARCOS MARTÍN, A.: «¿Fue la fiscalidad regia un factor de crisis...?», op. cit., passim.

22. Dicha evolución puede seguirse en GELABERT, J. E.: La bolsa del rey..., op. cit., pp. 381-384 (Apéndice I); ÁLVAREZ NOGAL, C.: El crédito de la Monarquía Hispánica en el reinado de Felipe IV. Ávila, 1997, passim; MARCOS MARTÍN, A.: «España y Flandes (1618-1648): la financiación de la guerra», en ALCALÁ-ZAMORA, J. y BELENGUER, E. (coords.): Calderón de la Barca y la España del Barroco. Madrid, 2001, vol. II, pp. 38-39; SANZ AYÁN, C.: Los banqueros y la crisis de la Monarquía Hispánica de 1640. Madrid, 2013, y de esta última autora, Los banqueros de Carlos II. Valladolid, 1989, libro que cierra, por lo que hace al siglo XVII, la serie iniciada, para el XVI, por R. Carande, F. Ruiz Martín y M. Ulloa, y continuada recientemente por autores como CARLOS MORALES, C. J. de: Felipe II: El Imperio en bancarrota..., op. cit., y DRELICHMAN, M. y VOTH, H.-J.: Lending to the Borrower from Hell. Debt, taxes, and default in the Age of Philip II. Princeton-Oxford, 2014. 
hecho más que crecer desde su creación en el reinado de los Reyes Católicos, pasando de 2,2 millones de ducados en 1504 a más de 80 millones en 1598; con todo, en el transcurso del siglo XVII todavía habría de multiplicarse por tres, hasta alcanzar los 222,9 millones de ducados en $1687^{23}$. En consecuencia, la Corona, para poder honrar dicha deuda, esto es, para atender debidamente a su servicio (pago de los intereses), tuvo que destinar recursos crecientes a tal menester, con lo que poco a poco fue comprometiendo, hasta llegar en no pocos casos a empeñarlas totalmente, las rentas sobre las que aquella se situaba. Únicamente el incremento continuado de las recaudaciones fiscales (a base principalmente de aumentar los impuestos existentes o de crear otros nuevos) hubiera permitido seguir tan alocada carrera. Pero esto, como hemos dicho, no sucedió así; por el contrario, la presión del situado de juros sobre los ingresos de la Corona (el famoso empeño) se fue haciendo cada vez más elevada, hasta el punto de que terminó rebasando el producto entero de estos. Es más, en un intento por impedir que dicha situación se concretara la Corona, incapaz de incrementar los ingresos en la medida en que el crecimiento incesante del situado lo requería, comenzó desde muy pronto a actuar sobre la propia deuda, adoptando medidas (crecimientos, reducciones unilaterales del tipo de interés, impago de ciertos juros o de aquellos que no cabían y no eran mudados a otras rentas, etc.) tendentes en principio a reducir la carga de los intereses que anualmente había de pagar ${ }^{24}$; pero acabó reteniendo, de forma regular, a partir de 1635 precisamente, una parte (primero la mitad, la llamada media annata, a la que se añadieron luego nuevos y sucesivos recargos) de los intereses que devengaban los títulos sin el consentimiento de sus titulares, procedimiento este aún más violento que aquellos de compensar el descenso de los ingresos o simplemente, puesto que la mayoría de estos estaban empeñados, de aumentar sus disponibilidades reales ${ }^{25}$.

Obviamente, la cotización de los títulos acabó de desplomarse a raíz de tales decisiones, y con ella la credibilidad de esta clase de deuda. Por consiguiente, los juros dejaron de constituir un sistema de deuda a largo plazo eficaz, garantizada por la Corona y vendida libremente a los ahorradores; y capaz, sobre todo, de absorber los incrementos de gasto que causaban las guerras continuas sin alterar gravemente la vida económica castellana. Cuando caemos en la cuenta de que las Provincias Unidas o Inglaterra (este después de 1660 y de forma todavía más sólida tras la

23. Véase supra nota 15.

24. Una valoración reciente de estas medidas en MARCOS MARTÍN, A.: «Crecimientos, reducciones y no cabimientos de juros. Tres episodios de gestión irresponsable de la deuda consolidada en el siglo XVII», Cuadernos de Historia Moderna, 42, 2, 2017, pp. 553-584.

25. MARCOS MARTÍN, A.: «Crisis y reestructuración de la deuda pública consolidada en el siglo XVII. La media anata de juros», en LANZA GARCÍA, R. (coord.): Las instituciones económicas, las finanzas públicas y el declive de España en la Edad Moderna. Madrid, 2017, pp. 57-94. 
fundación del Banco de Inglaterra en 1694) sí lograron, en contraposición, establecer un sistema de deuda eficaz, sostenido con holgura por unos ingresos fiscales que crecieron de forma notable a lo largo del siglo XVII, situándose a finales de dicha centuria además claramente por encima de los recaudados por la Real Hacienda de Castilla, es decir, justo al contrario de la realidad que imperaba a comienzos de la misma ${ }^{26}$, no resulta difícil imaginar, si no lo supiéramos ya, de qué lado iba a inclinarse la balanza en las guerras mantenidas con la Monarquía Hispánica durante el mil seiscientos. Es verdad que Francia, la gran antagonista después de 1635, no consiguió crear un sistema de deuda a largo plazo semejante, en parte por razones relacionadas, como en España, con su particular estructura social y económica, pero no es menos cierto que el tamaño de su población y de su economía en el siglo XVII, tras haber superado el trauma de las guerras de religión que desangraron su territorio durante la segunda mitad del XVI, era, no obstante la «crisis general» que también la afectó, prácticamente tres veces superior al de España, razón de peso que justifica sobradamente que el país vecino se hiciese con el testigo de la hegemonía europea después de Westfalia (1648) y la Paz de los Pirineos (1659), por lo menos hasta que Inglaterra, tras la Revolución Gloriosa (1688) y los tratados de Utrecht (1713-1714), comenzara a imponer toda su potencia no solo en el viejo continente sino en el mundo.

Como no podía ser de otra manera, esta clave explicativa del «cambio de hegemonía» que acontece en Europa a partir de la segunda mitad del siglo XVII está presente, de un modo u otro, en cada uno de los trabajos que componen el presente informe, cuyos autores aportan asimismo otros argumentos de no menor interés para comprender esa realidad ${ }^{27}$.

Así, Fernando Negredo del Cerro, que analiza minuciosamente en su trabajo las relaciones hispano-imperiales en el breve periodo que va de Nördlingen a Corbie (1634-1636) por entender que fue en estos años cuando se gestó el fracaso de una política común entre las dos ramas de la casa de Austria, se muestra rotundo al afirmar que «la cuestión clave en las relaciones entre Madrid y Viena/Praga» en

26. COMÍN COMÍN, F. y YUN CASALILLA, B.: «Spain: from composite monarchy to nation-state, 1492-1914», en YUN CASALILLA, B., O’BRIEN, P. K. y COMÍN COMÍN, F. (eds.): The Rise of Fiscal States. A Global History, 1500-1914. Cambridge, 2012, p. 237; y ANDRÉS UCENDO, J. I.: «Una hacienda permanentemente endeudada...», op. cit., pp. 71-73.

27. El origen de dichos trabajos se remonta al Seminario Internacional «Europa y la Monarquía Hispánica ante el cambio de hegemonía (1635-1659)» celebrado en la Universidad de Valladolid el 28 de octubre de 2016 y organizado por COREDEX. Columnaria: Red de Excelencia sobre movilidad de las sociedades y las fronteras de los mundos ibéricos (MINECO, Código HAR2015-69220-REDT); Proyecto Hispanofilia (III): la influencia ibérica en su contexto político, siglos XVI-XX (MINECO, Código HAR2014-52414-C2-1-P); y Grupo de Investigación Reconocido (GIR) de la Universidad de Valladolid «Grupo de estudios sobre la familia, cultura material y formas de poder en la España Moderna». 
los años de la guerra de los Treinta Años, e incluso desde antes, giró «en torno a la capacidad de la Monarquía Católica para financiar fidelidades y apoyos en el espacio alemán». A su juicio, ni los intereses dinásticos, ni los motivos religiosos (la defensa de la religión católica), ni las consideraciones estratégicas pesaron tanto a la hora de proporcionar solidez a la cooperación entre las dos partes como los dineros que los Habsburgo de Madrid fueron capaces de transferir a los territorios alemanes. Y no es que, viene a matizar, aquellos argumentos dejaran de intervenir en la toma de decisiones relativas a la marcha de la guerra; lo que ocurre es que su puesta en práctica dependió siempre de los dineros que pudieron llegar desde Madrid, por lo que no resulta demasiado aventurado suponer por dónde iban a transcurrir los acontecimientos cuando la capacidad de crédito de la Monarquía se resintiese y esas provisiones de fondos disminuyesen notablemente, como en efecto así acabaría sucediendo. En cualquier caso, el análisis detallado, profundo, perspicaz que realiza Fernando Negredo de los tratados hispano-imperiales de los años 1634 y 1635 le permiten descubrir por qué Madrid y Viena fueron incapaces de desarrollar políticas comunes, con objetivos militares conjuntos, en unos años, los que siguieron a la victoria de Nördlingen y la declaración de guerra de Francia, decisivos para la marcha general del conflicto europeo y en los que se estaba dirimiendo la hegemonía en Europa.

Este concepto de hegemonía es definido de forma precisa (dotándolo en consecuencia de un contenido histórico concreto) por Alicia Esteban Estríngana en su contribución con una perífrasis muy decidora que toma de la documentación de la época: la capacidad de «dar ley a los otros». Dicha capacidad, nos recuerda, era entendida por los hombres del siglo XVII como un estado o situación: el príncipe que la tenía se situaba o estaba por encima de todos los demás príncipes o estados, supremacía que podía generar aceptación en unos (de ahí la importancia/necesidad por parte de aquel de proyectar en estos una imagen de confianza o de suscitar en ellos sentimientos de afinidad, afecto o, simplemente, de interés) pero también provocar rechazo en otros (sobre todo en quienes contemplaban tal situación como una dominación o una amenaza). Precisamente en esta segunda posición se encontraba el reino de Francia con relación a la Monarquía de España, a la que acusaba de aspirar a la consabida «monarquía universal» en detrimento de los derechos y libertades de los demás estados europeos. Tal será, al menos, la idea que Luis XIII y su valido Richelieu propagarán para justificar y legitimar su política exterior a partir de los años veinte del Seiscientos, política que será seguida más tarde por Mazarino, y que, como apunta Alicia Esteban, pretendía no solo emanciparse de la «ley» del monarca Católico sino crear las condiciones apropiadas (en el contexto de una guerra que la misma Francia se encargará de extender y prolongar desde 1635 y de agotamiento financiero y creciente pérdida de capacidad militar de la Monarquía de España) para que fuese el rey Cristianísimo quien «diese la ley» a los otros. 
En qué medida la Corona de Francia consiguió ese objetivo en vísperas de Westfalia es la pregunta que se hace Alicia Esteban y que encuentra una aquilatada respuesta en las últimas páginas de su artículo. Son muchas e importantes, no obstante, las cuestiones por ella tratadas antes de llegar a este punto. Esclarecedor resulta, por ejemplo, su análisis del entramado de lealtades que el monarca francés consiguió tejer dentro del Sacro Imperio en los años previos a la declaración formal de guerra. Igualmente ajustado y no menos documentado es el balance que hace de «las dos guerras de Flandes» - la franco-española librada en el frente meridional de los Países Bajos y la hispano-holandesa, en el frente septentrional - durante la gobernación del cardenal-infante (1635-1641), un periodo que en su parte final coincide con el estallido de los movimientos secesionistas de Cataluña y Portugal que complicarán todavía más la situación de la Monarquía y comprometerán seriamente su capacidad para mantener la hegemonía. Es, en fin, el análisis de las vicisitudes de la guerra en ese doble frente, entre 1642 y 1646, el que permite a la profesora Esteban Estríngana valorar hasta qué punto Francia alcanzó la supremacía militar en la frontera de los Países Bajos en los años previos a la firma del Tratado de Münster (30 de enero de 1648). Dos circunstancias, amén de las derivadas estrictamente de los acontecimientos bélicos, le hacen creer que así pudo ser en efecto: una, la falta cada vez mayor de medios llegados desde España, que cercenaba las posibilidades del ejército de Flandes en ese doble frente y llevaba a muchos a pensar, tanto en Bruselas como en Madrid, si no sería mejor abandonar definitivamente aquel territorio para poder salvar Cataluña y Portugal ahora en peligro de perderse; y la otra, la celebración de negociaciones bilaterales con las Provincias Unidas que apuntaban ya claramente, desde mayo de 1646, a la consecución de una paz definitiva y no a una simple tregua, negociaciones alentadas sin duda por el temor, desde luego no infundado, que en la República despertaba la posibilidad de que el «Flandes español» deviniera en un «Flandes francés».

Sin embargo, no todo estaba decidido en la guerra que enfrentaba al rey Cristianísimo con el rey Católico (la cual se prolongaría hasta 1659) y tampoco la hegemonía española había sido suplantada automáticamente por la hegemonía francesa después de Münster-Westfalia (1648). Es lo que defiende Lourdes Amigo Vázquez en su artículo sobre la intervención española en la Fronda (1648-1653), en que viene a coincidir, aportando información nueva, con lo sostenido por otros autores. Mérito indiscutible de dicho trabajo es, en efecto, el uso que en él se hace de la abundante documentación inédita conservada en el Archivo General de Simancas, lo que ha permitido a su autora no ya solo abogar por que se deje de considerar la Fronda como un episodio exclusivamente francés, sino también - y sobre todovalorar debidamente hasta dónde llegó esa intervención, luego de prestar atención a la sucesión de los acontecimientos y a los personajes intervinientes en ellos, y de delinear sus características principales. 
Es obvio que Felipe IV no podía desaprovechar la ocasión que se le ofrecía para intervenir en los conflictos internos de Francia y debilitar así a su tradicional enemigo; se trataba, además, de hacer lo mismo que este estaba haciendo en Cataluña y Portugal (o había hecho antes en Italia), al margen de cualquier consideración de tipo confesional. Si las cosas no llegaron a más o no tuvieron el éxito esperado, está claro que ello se debió, aparte de a la propia debilidad interna de los levantamientos, a la imposibilidad de la Monarquía de España para cumplir con todo lo pactado con los frondistas franceses, particularmente en lo relativo a los envíos de dinero que, aunque importantes, no fueron suficientes para sostener las revueltas. También en este caso, pues, la falta de dinero, consecuencia de la precaria situación de la Hacienda y de la necesidad imperiosa de acudir a diversos frentes a la vez, se presenta como el factor que condicionó la evolución de los acontecimientos políticos y militares en un sentido diferente al pretendido en un principio. No obstante, y aun cuando por sí sola no consiguió causar en el país vecino la inestabilidad suficiente como para obligar a la Corona francesa a firmar la paz, es evidente que dicha intervención, como deja ver asimismo Lourdes Amigo, contribuyó a aligerar la presión que la potencia militar de Francia podría haber ejercido sobre distintos territorios de la Monarquía de no haber mediado precisamente esa circunstancia.

En su contribución Phillip Williams vuelve sobre algunos de los debates que han dominado el panorama historiográfico de las últimas décadas, como el del nacimiento del estado moderno (state formation) u otros directamente vinculados a él, tal el de la revolución militar o el del mercantilismo. Y lo hace llamando la atención sobre esa corriente historiográfica, particularmente sólida en el mundo anglosajón, que cuestiona la idea de un proceso de construcción del estado moderno fundado en un sistema de administración eficaz y en el desarrollo inexorable hacia la modernidad a través de los intereses nacionales; y que tiende a insistir, por el contrario, en las limitaciones y contradicciones a las que dichos estados tuvieron que enfrentarse, empezando naturalmente por el problema de la financiación (nacido del desfase entre las exigencias de la guerra, la riqueza y los recursos de la sociedad, de un lado, y la capacidad de recaudación, del otro) y continuando por el de su dependencia de las respectivas élites regionales. Estas premisas le sirven a Phillip Williams de introducción para plantear diversos aspectos relativos a la monarquía inglesa y repasar las interpretaciones recientes sobre los orígenes de las guerras civiles (1642-1646 y 1648), todo ello con vistas a contextualizar el debate en torno a las relaciones, no suficientemente conocidas, entre Felipe IV de España y Carlos I de Inglaterra y Oliver Cromwell.

A Manuel Herrero Sánchez le cabe el honor de ser uno de los pocos historiadores que en los últimos años se han ocupado de traer al primer plano de la escena historiográfica el tema de las repúblicas y el republicanismo en la Europa Moderna, título precisamente de un libro editado por él en 2017. En su contribución a este 
informe vuelve una vez más sobre el tema y lo hace ampliando las perspectivas y aportando nueva información. Concretamente, el asunto que reclama su atención en este momento es el análisis del papel desempeñado por las repúblicas mercantiles de Génova y las Provincias Unidas en el conflicto hispano-francés por la hegemonía (1635-1659). Asunto relevante, sin duda, tanto más cuanto que entre esas dos fechas tiene lugar, como el propio Manuel Herrero enfatiza, un cambio significativo en la relación que ambas repúblicas habían mantenido hasta entonces con la Monarquía Hispánica.

Así, mientras que en la república de Génova se asiste, a partir de mediados de la década de 1620 y más claramente desde la entrada de Francia en la guerra de los Treinta Años, a un progresivo cuestionamiento de la estrecha colaboración que la había unido a la Monarquía Hispánica desde 1528 y se apostaba por una posición de neutralidad; en las Provincias Unidas, en cambio, se pasó, tras la firma de la paz de Münster de 1648 y no sin oposiciones internas, de un conflicto que la había enfrentado con la Monarquía durante 80 años a una estrecha alianza con ella que, entre otras ventajas, le iba a reportar beneficiosas concesiones comerciales. Todo ello en medio de un panorama internacional cambiante en el que, por ejemplo, el componente confesional en las relaciones entre estados poco a poco había ido perdiendo peso y los argumentos religiosos prácticamente habían desaparecido del horizonte bélico; en el que se confirmaba, por otro lado, el debilitamiento de los lazos que habían vinculado a las dos ramas de la casa de Austria; y en el que, en fin, parecía haberse impuesto una nueva estrategia en favor del equilibrio de poderes. Precisamente la amenaza que para el mantenimiento de la estabilidad internacional representaban las pretensiones territoriales de Luis XIV sobre los Países Bajos o las campañas de los corsarios al servicio de Francia en el Mediterráneo hizo que Génova no tardara en inclinarse de nuevo del lado español, y que las Provincias Unidas reafirmaran su a lianza con la Monarquía Hispánica, ahora más que nunca destinada a frenar la política expansionista del rey de Francia y a la que invitarán a participar, con ese mismo fin, al Emperador y, más tarde, a Inglaterra. De este modo, el monarca Católico se convertirá en el principal valedor de este tipo de estructuras políticas policéntricas de carácter urbano frente al impulso soberanista de Francia, cuestión esta última, la del choque de dos modelos de soberanía, de la que el profesor Herrero Sánchez se ocupa también en su colaboración con amplitud y finura de análisis.

El artículo firmado por Davide Maffi examina la contribución de las provincias italianas al esfuerzo bélico de la Monarquía, en especial entre 1621 y 1660, periodo en que dicha contribución es calificada por él de masiva. En este sentido, el autor aporta una abundante información cuantitativa que permite valorar exactamente esa contribución, que no se limitó además a las prestaciones dinerarias sino que se complementó con la entrega de soldados, armas, pertrechos y víveres. Y ello con una particularidad que el propio Maffi destaca igualmente, ya que si el reino de Nápoles y, en menor medida, el de Sicilia realizaron importantes envíos fuera de sus territorios, tanto de 
dinero como de medios para abastecer los ejércitos, fueron muy pocas en cambio las ocasiones en que el Milanesado remitió dinero efectivo a otros frentes de guerra: antes bien a él se enviaron desde esos dos reinos (también por supuesto desde Castilla) importantes cantidades de numerario, circunstancia que se explica perfectamente por el hecho de ser Milán el centro de acuartelamiento del ejército más importante de la Monarquía, después del de Flandes, y por su posición estratégica fundamental con respecto a Italia y al centro de Europa, situación que originaba un considerable gasto que no se podía satisfacer solo desde el propio territorio. En cualquier caso, los esfuerzos exigidos a las provincias italianas para sostener los conflictos bélicos en que intervenía la Monarquía, crecientes hasta las revueltas de 1647-1648, provocaron la instauración de una auténtica fiscalidad de guerra que adoptó diferentes formas; pero al no proceder de ellas todo lo que se las demandaba, las haciendas de dichos territorios se vieron obligadas a poner en ejecución expedientes extraordinarios (ventas de feudos, títulos y oficios sobre todo) y a emitir más y más deuda pública, cuando no a explotar en su favor la capacidad de crédito de las comunidades locales.

Esta fiscalidad de guerra modificó profundamente, según resume Davide Maffi, el cuadro general de la península italiana. En Sicilia y en Nápoles sus repercusiones fueron particularmente negativas. El reino de Sicilia, por ejemplo, ya no se recuperaría, en el tiempo restante de presencia hispana en la isla, de las graves crisis padecidas en los años treinta y cuarenta: después de 1648, con más de la mitad de los ingresos de su hacienda empeñados y gran parte de los bienes del patrimonio regio enajenados, apenas le quedaba lo necesario para cubrir los gastos militares y administrativos del reino. En cuanto a Nápoles, los ingresos ordinarios del reino cayeron también en picado después de esa fecha, y si bien todavía durante el reinado de Carlos II pudo seguir contribuyendo al esfuerzo bélico de la Monarquía, lo cierto es que el agotamiento de la región en las últimas décadas del siglo era una realidad palmaria, con unas localidades muy endeudadas y una economía local minada por la fuerte devaluación de la moneda. En contraste con los reinos meridionales, la hacienda del estado de Milán resistió bastante bien como lo hizo también, en líneas generales, la propia economía milanesa al beneficiarse de los gastos realizados por el gobierno en la defensa del país. Además, el hecho no menos notable por revelador de que la recaudación de los impuestos se gastase dentro y no se enviase fuera, al contrario de lo que ocurrió en Nápoles y Sicilia (y no digamos ya en Castilla), es otro factor que explica la vitalidad de la economía milanesa en la segunda mitad del Seiscientos.

El peso de la guerra, de una guerra además que en el periodo de 1635-1659 dejó de ser una mercancía de exportación reservada a otros espacios e hizo de nuevo su aparición en la Península, se sintió con especial contundencia en la corona de Castilla a través de la fiscalidad y otras demandas que de ella se derivaban. De ello se ocupa José Javier Ruiz Ibáñez quien, de entrada, nos invita a tener presente algo que a menudo se olvida: la necesidad de estudiar los efectos de la política imperial sobre el conjunto de la población y de no limitar los análisis a la simple consideración 
de la cuantía de los impuestos que la financiaban y su administración. Su examen de las repercusiones que las exigencias fiscales regias tuvieron sobre los territorios castellanos va precisamente en esa línea al discurrir por una vertiente más social y política que estrictamente financiera o económica.

Para el profesor Ruiz Ibáñez, en efecto, la sociedad castellana que sostenía la Monarquía experimentó cambios importantes a partir de la década de 1630, impelida por la necesidad de adaptarse a las nuevas condiciones que el incremento de las demandas regias fue creando; es más, la propia Monarquía se redefinió en el transcurso de dicho proceso de cambio o adaptación tanto en aspectos relativos a su construcción administrativa como en la percepción que de ella tenían sus habitantes. Respecto a esta última cuestión, por ejemplo, piensa José Javier Ruiz Ibáñez que por esas fechas la población pudo percibir cómo su función en tanto que vecinos, que había presidido hasta entonces su definición política y su inserción en el entramado imperial, perdía poco a poco protagonismo, siendo desplazada por su función como súbditos, una función, esta segunda, que hasta entonces había sido secundaria en la vida cotidiana. Es decir, cambió su percepción de qué era ser integrante de la Monarquía precisamente porque estaban cambiando las formas - y la amplitud - con que esta les reclamaba su apoyo. El profesor Ruiz Ibáñez aduce como ejemplo ilustrador de estos cambios los producidos en las formas de reclutamiento ante el colapso, también por estos años, del sistema tradicional de reclutamiento voluntario y la progresiva generalización del reclutamiento por sorteo o cuota. Y es que, según señala de modo conclusivo, servir al rey como soldado dejó de ser, a los ojos de la población, un privilegio voluntariamente exigido o una vía de ascenso social para convertirse, en la práctica, en una obligación de la que aquella buscaba huir o eximirse. Pero también comenzó a cambiar la manera en que la población se pensaba en tanto que castellana y en tanto que española, y ello quizá fuese más importante aún. No en vano, como sugiere asimismo José Javier Ruiz, con ocasión de las guerras de Cataluña y Portugal las demandas de hombres y dineros destinados a sufragarlas permitieron que se confundiera el auxilium al rey frente a vasallos rebeldes con la defensa del mismo solar patrio y, por consiguiente, de un cuerpo político común. En fin, a su juicio, que contradice la opinión de quienes hablan de una desestructuración política de Castilla en el siglo XVII, todos estos procesos discurrieron paralelos al de la afirmación de la autoridad monárquica. Desde luego esta no se vio obstaculizada por la creciente fiscalidad como a veces se ha dicho; por el contrario, la redistribución de recursos inherente a la actividad extractora de la Monarquía, que se materializaba de maneras muy diversas, benefició ampliamente a las élites locales que la gestionaban, las cuales se convirtieron, desde sus reductos de poder municipales, en garantes de la estabilidad y supervivencia de todo el sistema, ese en el que tan cómoda e interesadamente se hallaban instaladas. 
Los trabajos reunidos en este informe constituyen aportaciones muy relevantes que ayudarán a comprender mejor, en conjunto y por separado, el periodo que hemos titulado de «cambio de hegemonía» en Europa. Tiempos estos, los comprendidos en él, de enorme densidad histórica, pero cuya caracterización necesitaba de precisiones como las contenidas en las contribuciones de este monográfico. Sus autores, como el lector fácilmente podrá comprobar, han partido de un conocimiento exhaustivo de la bibliografía existente sobre los temas tratados, han aportado información documental nueva extraída de diferentes archivos, tanto nacionales como extranjeros, y han llevado a cabo asimismo una reflexión teórica importante. El resultado son unos textos llenos de contenido, que ofrecen interpretaciones novedosas y matizadas sobre la Monarquía Hispánica en los inicios de su etapa de decadencia, y que dotan a este y otros conceptos (empezando por el propio de hegemonía) de un contenido histórico preciso. Pero se trata también de textos abiertos a la discusión historiográfica, pues sus autores son conscientes de que la historia, como construcción intelectual escrita sobre los hechos del pasado, se hace cada día al compás de investigaciones que, como las suyas, puedan merecer verdaderamente el nombre de tales.

\section{BIBLIOGRAFÍA}

ALLEN, P. C., Felipe III y la pax hispánica, 1598-1621. Madrid, Alianza, [2001].

ÁLVAREZ NOGAL, C.: El crédito de la Monarquia Hispánica en el reinado de Felipe IV. Ávila, Junta de Castilla y León, 1997.

ANDRÉS UCENDO, J. I.: «Una hacienda permanentemente endeudada: impuestos y deuda pública en la Castilla del siglo XVII», en ÁLVAREZ NOGAL, C. y COMÍN COMIN, F. (eds.): Historia de la deuda pública en España (siglos XVI-XXI). Madrid, Instituto de Estudios Fiscales, 2015, pp. 67-83.

ANDRÉS UCENDO, J. I. y LANZA GARCÍA, R.: «Estructura y evolución de los ingresos de la Real Hacienda de Castilla en el siglo XVII», Studia Historica. Historia Moderna, 30, 2008, pp. 147-190.

CARLOS MORALES, C. J. de: Felipe II: El Imperio en bancarrota. La Hacienda Real de Castilla y los negocios financieros del Rey Prudente. Madrid, Dilema Editorial, 2008.

COMÍN COMÍN, F. y YUN CASALILLA, B.: «Spain: from composite monarchy to nation-state, 1492-1914», en YUN CASALILLA, B., O’BRIEN, P. K. y COMÍN COMÍN, F. (eds.): The Rise of Fiscal States. A Global History, 1500-1914. Cambridge, Cambridge University Press, 2012.

DOMÍNGUEZ ORTIZ, A.: Politica y Hacienda de Felipe IV. Madrid, Editorial de Derecho Financiero, 1960.

DRELICHMAN, M. y VOTH, H.-J.: Lending to the Borrower from Hell. Debt, taxes, and default in the Age of Philip II. Princeton-Oxford, Princeton University Press, 2014.

GARCÍA GARCÍA, B. J.: La Pax Hispanica:politica exterior del duque de Lerma. Leuven, Leuven University Press, 1996. 
GELABERT, J. E.: La bolsa del rey. Rey, reino, fisco en Castilla (1598-1548). Barcelona, Crítica, 1997.

LOVETT, A. W.: «The General Settlement of 1577: An Aspect of Spanish Finance in the Early Modern Period», Historical Journal, 25 (1), 1982, pp. 1-22.

MARCOS MARTÍN, A.: «España y Flandes (1618-1648): la financiación de la guerra», en ALCALÁ-ZAMORA, J. y BELENGUER, E. (coords.): Calderón de la Barca y la España del Barroco. Madrid, Centro de Estudios Políticos y Constitucionales, 2001, vol. II, pp. 15-39.

MARCOS MARTÍN, A.: «Deuda pública, fiscalidad y arbitrios en la Corona de Castilla durante los siglos XVI y XVII», en SANZ AYÁN, C. y GARCÍA GARCÍA, B. J. (eds.): Banca, Crédito y Capital. La Monarquía Hispánica y los antiguos Países Bajos (1505-1700). Madrid, 2006, pp. 345-375.

MARCOS MARTÍN, A.: «¿Fue la fiscalidad regia un factor de crisis en la Castilla del siglo XVII?», en PARKER, G. (coord.): La crisis de la Monarquía de Felipe IV. Barcelona, Crítica, 2006, pp. 173-253.

MARCOS MARTÍN, A.: «Restaurar la Hacienda para conservar la Monarquía. El intento de creación (1616) de una Junta de Provisiones», en GARCÍA GUERRA, E. Ma . y DE LUCA, G. (a cura di): Il mercato del crédito in Età Moderna. Reti e operatori finanziari nello spazio europeo. Milano, Franco Angeli, 2009, pp. 207-235.

MARCOS MARTÍN, A.: «Crecimientos, reducciones y no cabimientos de juros. Tres episodios de gestión irresponsable de la deuda consolidada en el siglo XVII», Cuadernos de Historia Moderna, 42, 2, 2017, pp. 553-584.

MARCOS MARTÍN, A.: «Crisis y reestructuración de la deuda pública consolidada en el siglo XVII. La media anata de juros», en LANZA GARCÍA, R. (coord.): Las instituciones económicas, las finanzas públicas y el declive de España en la Edad Moderna. Madrid, Servicio de Publicaciones de la Universidad Autónoma de Madrid, 2017, pp. 57-94.

PARKER, G.: España y la rebelión de Flandes. Madrid, Nerea, 1989.

PARKER, G.: Felipe II. Madrid, Alianza, 2003.

RUIZ MARTÍN, F.: «Las finanzas españolas durante el reinado de Felipe II», Cuadernos de Historia. Anexos de la Revista Hispania, 2, 1968, pp. 181-203.

SANZ AYÁN, C.: Los banqueros de Carlos II. Valladolid, Universidad de Valladolid, 1989.

SANZ AYÁN, C.: Los banqueros y la crisis de la Monarquía Hispánica de 1640. Madrid, Marcial Pons, 2013. 